\title{
O Brasão das Armas do Estado de São Paulo na identidade visual da Pinacoteca
}

\author{
The coat of arms of the State of São Paulo in the visual identity of the Pinacoteca \\ Jade Samara Piaia, Edson do Prado Pfützenreuter
}

Palavras-chave: Memória gráfica; Identidade visual; Assinatura gráfica; Pinacoteca; Brasão das Armas do Estado de São Paulo.

\begin{abstract}
Resumo: Este artigo analisa a identidade visual da Pinacoteca a partir da memória gráfica dessa instituição, delimitando peças gráficas institucionais, como catálogos e documentos, nos quais figura o Brasão das Armas do Estado de São Paulo. A Pinacoteca do Estado de São Paulo é o museu de arte mais antigo do estado, em pleno funcionamento, possuindo peças gráficas de mais de cem anos preservadas em acervo. Estas encontram-se preservadas no acervo do Centro de Documentação e Memória (Cedoc), que é a fonte primária de dados deste artigo. O objetivo é observar como os aspectos históricos e políticos influenciaram a identidade visual da Pinacoteca, a partir do material que inclui peças gráficas institucionais que apresentam a identificação da instituição. Foram analisados três catálogos do acervo do Cedoc publicados na década de 1950 pela Gráfica João Bentivegna e os documentos oficiais que trouxeram o Brasão do Estado datados a partir da década de 1950 até 1980 . Este artigo abrange a identificação da linguagem visual da Pinacoteca em sua relação com aspectos políticos e a relação com os períodos históricos vividos pela instituição e pelo campo gráfico em meados da década de 1950.
\end{abstract}

Keywords: Graphical memory; Pinacoteca; Visual identity; Graphic signature; Coat of Arms of the State of São Paulo.

\begin{abstract}
This article analyzes the Pinacoteca's visual identity from it's graphic memory, delimiting the institutional graphic pieces, like the catalogs and official documents, in which the State of São Paulo's Coat of Arms is found. The State of São Paulo's Pinacoteca is the oldest art museum in the state that is still in full operation, possessing graphic pieces of more than one hundred years preserved in the collection. These are preserved in the Documentation and Memory Center's (Cedoc) collection, which is the primary data source of this article. The objective is to observe how the historical and political aspects influenced the Pinacoteca's visual identity, from the material preserved which includes institutional graphic pieces that present the institution's identification. Three Cedoc's catalogs collection published in the 1950's by Gráfica João Bentivegna and the official letterhead documents that lead the State of São Paulo's Coat dating from the 1950's to the 1980's were analyzed. This article covers the Pinacoteca's visual language identification in its relationship with political aspects and the relation with the historical periods lived by the institution and the graphic field in the mid 1950's.
\end{abstract}

\section{Sobre a Pinacoteca}

Fundada em 1905, inicialmente contando apenas com uma sala de quadros transferidos do Museu Paulista, a Pinacoteca evoluiu para o status de museu ao longo de sua existência, através da ampliação de seu acervo. Este período inicial, bastante conturbado, envolveu uma mudança de endereço na década de 1930, com o retorno à sede no bairro da Luz na década seguinte. O Estado adquiriu o edifício do Liceu de Artes e Ofícios em 1944, quando o destinou ao abrigo da Pinacoteca e outras instituições. Nesse período, o acervo do museu cresceu, ultrapassando mil obras. O artista plástico e pintor Túlio Mugnaini assumiu a direção da instituição no mesmo ano, ocupando o cargo até 1965. Até a década de 1980, passaram por ali nomes como Silvio Costa e Silva, Delmiro Gonçalves, Clóvis Graciano, Walter Wey, Alfredo Gomes, Aracy Amaral, Fábio Magalhães, Maurício Fridman, Maria Cecília França Lourenço e Lourdes Therezinha Silva de Amorim (CAMARGOS; MORAES, 2005).

Em 1948, o Conselho de Orientação Artística, ao qual a Pinacoteca era subordinada, foi extinto e a instituição passou a ser subordinada às secretarias de Governo. Esse fato viria

Anais do $8^{\circ} \mathrm{CIDI}$ e $8^{\circ}$ CONGIC

Guilherme Santa Rosa; Cristina Portugal (orgs.)

Sociedade Brasileira de Design da Informação - SBDI

Natal | Brasil | 2017

ISBN 978-85-212-1305-5
Proceedings of the $8^{\text {th }}$ CIDI and $8^{\text {th }}$ CONGIC

Guilherme Santa Rosa; Cristina Portugal (orgs.) Sociedade Brasileira de Design da Informação - SBDI

Natal| Brazil | 2017

ISBN 978-85-212-1305-5 


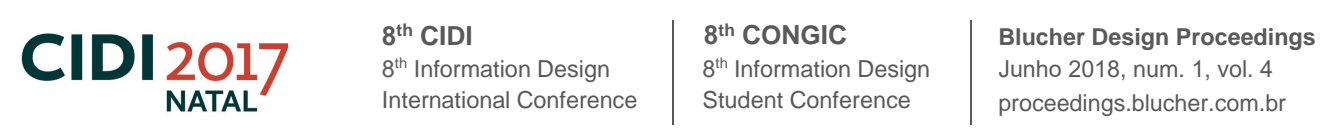

refletir em muitos de seus documentos oficiais e nas publicações de seus catálogos. Cabe pontuar que outros museus importantes foram instalados na cidade de São Paulo nesse período, como o Masp, em 1947, o MAM-SP, em 1948 e o MAC-USP, em 1963.

\section{Sobre a memória gráfica da Pinacoteca e o método de investigação}

Entende-se que a memória gráfica de um equipamento cultural preserva-se em suas publicações impressas. No caso da Pinacoteca, fazem parte da memória gráfica os catálogos do acervo e os documentos oficiais preservados pelo Cedoc, objetos de análise deste artigo. A pesquisa em memória gráfica, segundo Farias (2014), está relacionada principalmente a estudos de identidades locais do design na América Latina, sobretudo de artefatos visuais, e relaciona-se com campos de pesquisa como cultura visual, cultura impressa e cultura material.

Como referências metodológicas foram consultados artigos de historiadores e pesquisadores do campo do design, como Aragão et al. (2012), Lima et al. (2012), que abordaram métodos aplicados em análises de artefatos de memória gráfica, referenciaram o modo de categorização e classificação dos dados e auxiliaram no modo de olhar os objetos em questão.

As análises abordaram a caracterização visual das peças gráficas, apontamentos estéticos, tipográficos e os agentes gráficos envolvidos. Abordaram questões relacionadas à assinatura gráfica, terminologia que compreende uma nomenclatura, de uma instituição por exemplo, podendo envolver elementos esquemáticos, pictóricos ou abstratos no modo como é reproduzida através de processos gráficos (PIAIA, 2017). Também foram observados na análise gráfica (VILLAS-BOAS, 2009) os formatos e a estrutura organizacional, a mancha gráfica e a organização dos elementos, bem como a presença de outros símbolos junto à assinatura gráfica, o posicionamento da assinatura na peça, presença, interação e características dos elementos verbais, esquemáticos e pictóricos (TWYMAN, 1979).

\section{O Brasão das Armas do Estado de São Paulo}

O Brasão das Armas do Estado de São Paulo foi criado tardiamente, em decorrência do Movimento Constitucionalista em 1932, passando a figurar onde antes vigorava apenas o Brasão das Armas Nacionais. Confeccionado em aquarela pelo pintor José Wasth Rodrigues, em conjunto com o poeta e heraldista Guilherme de Almeida, foi apresentado ao Governador Pedro de Toledo, que o aprovou. Foi solicitada a alteração na frase "Pro Brasilia Fiant Eximia"1 (STICKEL, 2004: 718) e publicado no Diário Oficial (1932: 1) em 30 de agosto de 1932, com a descrição dos elementos simbólicos da heráldica.

Figura 1 Brasão de Armas do Estado de S.P., José Wasth Rodrigues, JWR, 1932. Fonte: Stickel (2004: 718).

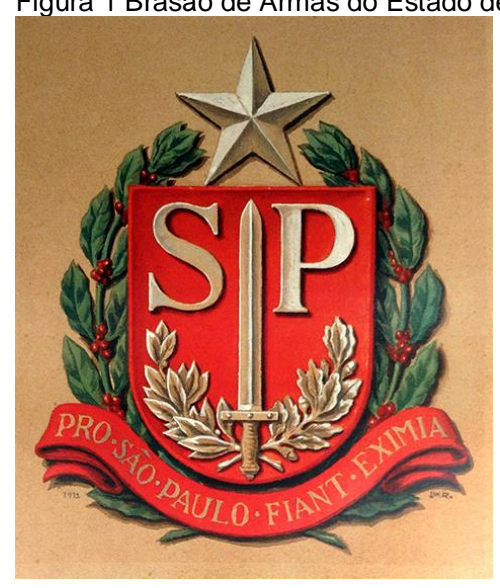

\footnotetext{
1 "Pelo Brasil façam-se grandes coisas" (FEDERICI, 1980: 52).
} 


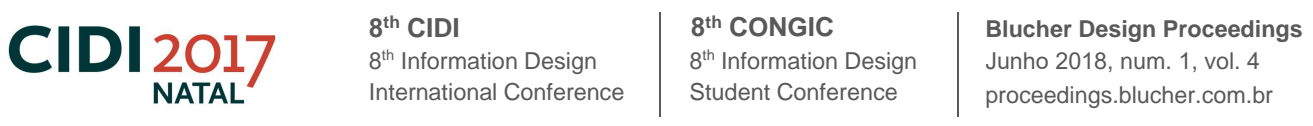

Figura 2 Versão monocromática do Brasão de Armas do Estado de São Paulo, 1932. Fonte: Federici (1980: 51).

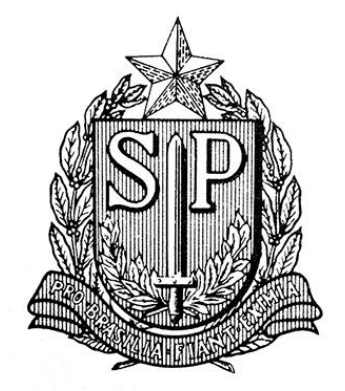

Cinco anos mais tarde o uso dos brasões estaduais foi suspenso pela Constituição do Estado Novo, outorgada pelo presidente Getúlio Vargas em 1937, na tentativa de coibir o uso de símbolos que não fossem os nacionais. Os símbolos paulistas foram restaurados por meio do Decreto-lei no 16.349, de 27 de novembro de 1946, logo após a publicação da nova Constituição do Brasil, cujo art. 195 libera estados e municípios a utilizarem símbolos próprios (FEDERICl, 1980). Após o surgimento da Constituição Estadual, em 9 de julho de 1947, a Lei no 145, de 3 de setembro de 1948 (ASSEMBLEIA..., 1948), trouxe um descritivo mais preciso do Brasão, tornando obrigatória a obediência às regras heráldicas e às normas de reprodução monocromática. Segundo Hilton Federici (1980), os modos de representação monocromática das tonalidades, de acordo com os ensinamentos da heráldica, para substituir o metal prata deve ser deixado em branco; para substituir o vermelho, dito "goles" em heráldica, deve-se reproduzi-lo por meio de linhas verticais; para o lugar do verde, "sinople", deve-se reproduzi-lo por traços em diagonal, descendo da esquerda para a direita de quem olha de frente.

Figura 3 Modelo incorreto do Brasão de Armas do Estado de São Paulo. Fonte: Assembleia... (1948: Anexo n. 4).

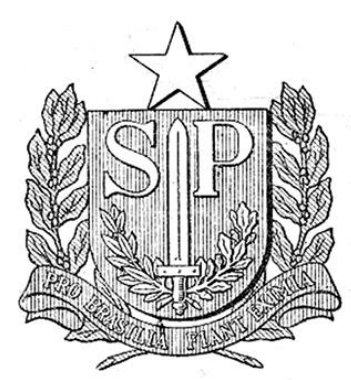

Embora correto enquanto padronização monocromática heráldica, o modelo do Brasão publicado em 1948 trazia grosseiras deturpações no desenho e não seguia a estrutura original dos elementos gráficos que constavam no modelo de 1932, utilizado até então. O equívoco gráfico foi oficialmente resolvido anos mais tarde, com a lei que entrou em vigor em 6 de julho de 1971 (ASSEMBLEIA..., 1971), esclarecendo os pontos incorretos no desenho e publicando um modelo correto como referência.

\section{Os catálogos da Pinacoteca publicados na década de 1950}

A década de 1950 compreende três publicações institucionais da Pinacoteca, intituladas "Catálogo", publicadas em 1950, 1951 e 1954. Caracterizadas pelo formato de $16 \times 23 \mathrm{~cm}$ e pela impressão em duas cores, trazem na capa, em posição de destaque, o Brasão das Armas do Estado de São Paulo.

As capas semelhantes configuram um conjunto, devido ao padrão de estrutura gráfica. As bordas lineares demarcam a mancha gráfica e foram impressas em preto junto com o Brasão e as informações no rodapé; o conjunto principal de informações, que inclui o título e a assinatura gráfica da Pinacoteca, foram impressos em vermelho, cores utilizadas na bandeira do Estado. 
Figura 4 Catálogo 1950, Pinacoteca do Estado de S. Paulo, João Bentivegna, São Paulo. Original escaneado. Fonte: Acervo Cedoc / Pinacoteca de São Paulo.

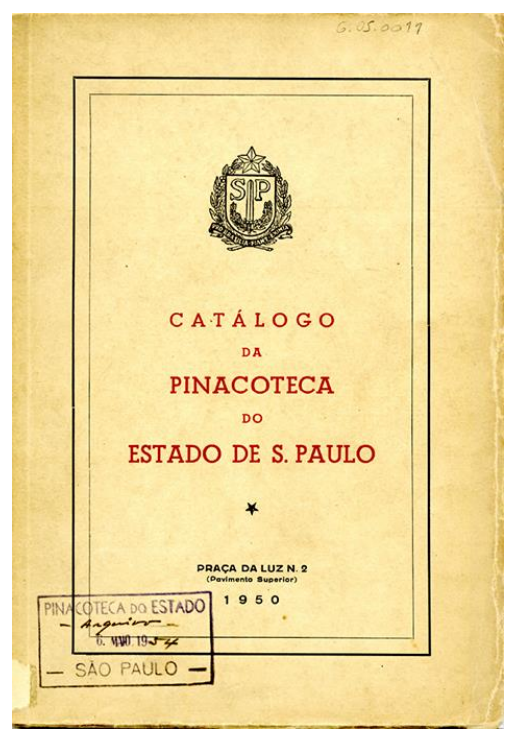

O catálogo de 1950 inaugura o padrão gráfico que seria visto nas publicações dessa década. Apresenta uma estrutura de composição centralizada, iniciada pelo Brasão monocromático na parte superior. O título foi centralizado e grafado em letras maiúsculas, com variações de tamanho entre as palavras, em uma tipografia de serifa retangular abrupta, mantendo a fonte utilizada anteriormente nos catálogos da Pinacoteca da década de 1940, que estampavam com destaque o Brasão das Armas Nacionais (PIAIA, 2016). Uma estrela separa o título das informações no rodapé, em fonte sem serifa.

Figura 5 Catálogo 1951, Pinacoteca do Estado de S. Paulo, João Bentivegna, São Paulo. Original escaneado. Fonte: Acervo Cedoc / Pinacoteca de São Paulo.

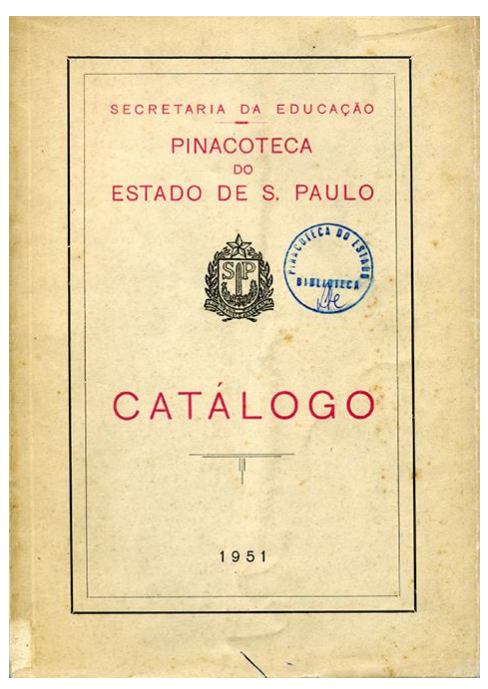

O catálogo de 1951 segue, em traços gerais, o visual da publicação anterior, mas traz algumas diferenciações sutis. A estrutura gráfica da composição centralizada foi mantida, mas o cabeçalho contém as informações separadas por um discreto elemento geométrico linear, indicando o vínculo do museu à Secretaria da Educação. O Brasão, ao centro, apresenta diferenças no preenchimento, como as hachuras na estrela particionada e o preenchimento, ao invés do contorno, nas folhas dos ornamentos externos ao escudo. O título da publicação vem logo abaixo do Brasão, com destaque conferido pelo tamanho dos caracteres e área ocupada. As informações textuais continuam impressas em vermelho, porém observa-se a introdução de 


\section{CIDI 2017 intir

uma tipografia reta, sem serifa e de traço contínuo, mantendo o uso exclusivo de caracteres maiúsculos na grafia. Um conjunto discreto de elementos gráficos lineares finos separa o título da publicação do ano, no rodapé.

Figura 6 Catálogo 1954, Pinacoteca do Estado de S. Paulo [s.l.;s.n.]. Original escaneado. Fonte: Acervo Cedoc / Pinacoteca de São Paulo.

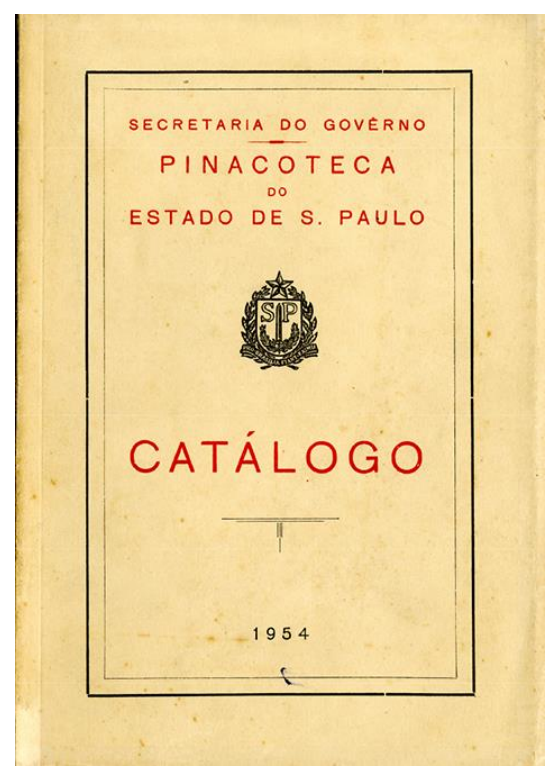

A publicação de 1954 possui estrutura idêntica ao Catálogo de 1951, considerando todos os elementos gráficos utilizados na capa. Há uma única alteração na informação do cabeçalho, para "Secretaria do Govêrno", e no espacejamento entre letras na assinatura gráfica da Pinacoteca.

Figura 7 Quarta capa do Catálogo da Pinacoteca, 1950, com detalhe da assinatura da gráfica João Bentivegna. Original escaneado. Fonte: Acervo Cedoc / Pinacoteca de São Paulo.

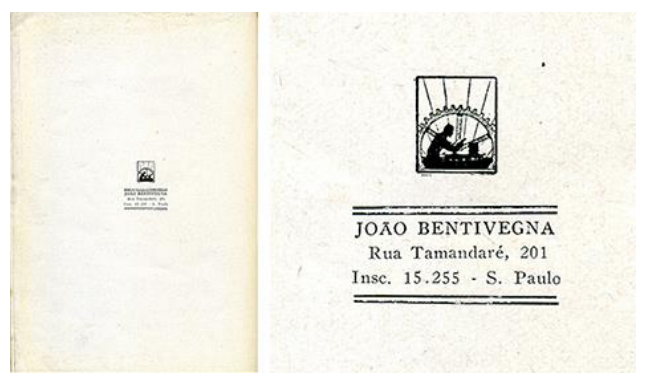

Ao final dos catálogos, a quarta capa trazia um ícone seguido da nomenclatura da gráfica e o endereço. Anteriormente denominada Gráfica Paulista (PIAIA, 2016), João Bentivegna apresenta uma mudança na nomenclatura e no ícone utilizado. O ícone visual que representa a gráfica traz a silhueta de uma pessoa, forma possível de associar à representação do profissional gráfico em atividade, que parece estar sobre uma prancheta com uma engrenagem ao fundo. No catálogo de 1954 não consta assinatura da gráfica, porém suas características físicas e estéticas são muito semelhantes às demais publicações produzidas pela gráfica de Bentivegna nessa década. Diante das evidências, é possível deduzir que o referido catálogo fora também composto e impresso pela mesma empresa.

Sabe-se que a "Indústria Gráfica de Bentivegna" foi fundada na década de 1920 e especializou-se na publicação de revistas. O setor gráfico estava em expansão e em 1937 o número de tipografias no país ultrapassava 2 mil. Polarizando a produção gráfica, São Paulo se 
configurava um centro editorial com mais de quatrocentas gráficas em 1942, incluindo tipografias, litografias e clicherias (GORDINHO, 1991: 67-69). Na década seguinte, a indústria gráfica passava por significativas transformações tecnológicas, que viriam a impactar nas produções gráficas futuras, e a cidade de São Paulo comemorava seu IV Centenário, marcando a década de $1950 \mathrm{com}$ grandes acontecimentos. Segundo Bastos (2010), que analisa o papel de São Paulo na história do design brasileiro, o período foi de expansão da indústria gráfica, sentida principalmente no estado de São Paulo.

\section{Os documentos oficiais da Pinacoteca e sua identidade subordinada ao governo}

Da década de 1950 até 1980, os documentos oficiais da Pinacoteca trouxeram, no cabeçalho, a subordinação às distintas secretarias de Estado, junto com o Brasão das Armas do Estado e a assinatura gráfica da instituição. Há uma padronização da nomenclatura para as assinaturas gráficas do período, como "Pinacoteca do Estado de São Paulo", vigente nos documentos datados até o final da década de 1950.

Os documentos dessa fase trazem o Brasão, sempre no canto superior esquerdo, como parte do cabeçalho do documento. Como visto anteriormente, o Brasão estadual voltou a ser usado com a restauração dos símbolos paulistas em 1946, após a publicação da nova Constituição do Brasil, que liberou o uso de símbolos próprios por estados e municípios (FEDERICl, 1980).

Figura 8 Documento, 1952, Pinacoteca do Estado de São Paulo. Original fotografado. Fonte: Acervo Cedoc / Pinacoteca de São Paulo.
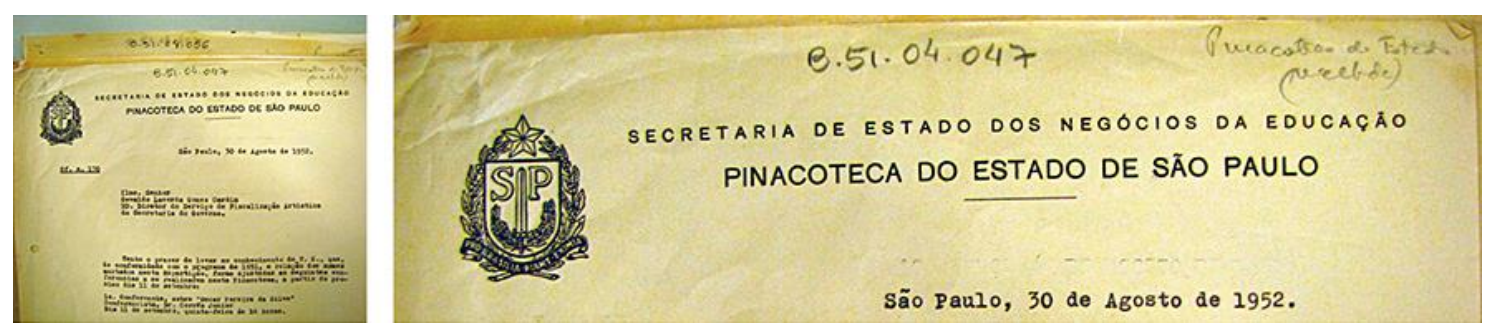

As secretarias às quais a Pinacoteca passa a ser subordinada são diversas, como a "Secretaria de Estado dos Negócios da Educação" e a "Secretaria de Estado dos Negócios do Govêrno" no decorrer da década de 1950. A partir do documento datado de 1959, o endereço e o telefone do museu passaram a fazer parte do cabeçalho.

Figura 9 Documento, 1959, Pinacoteca do Estado de São Paulo. Original escaneado. Fonte: Acervo Cedoc / Pinacoteca de São Paulo.

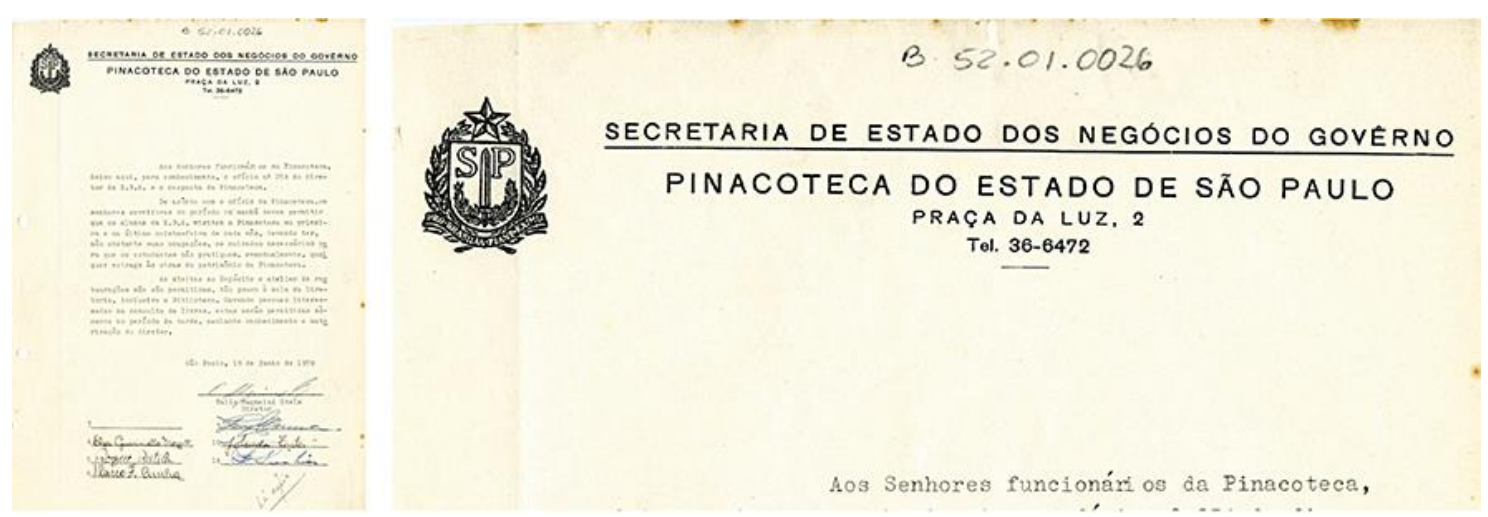

Nos documentos de 1952 e 1959, uma mesma fonte tipográfica foi utilizada nas assinaturas das secretarias e da Pinacoteca. A tipografia parece seguir um mesmo padrão de caracteres sem serifas de traço contínuo, uniforme - características que se assemelham às tipografias 


\section{CIDI 2017

sem serifas transicionais, segundo Lupton (2006) -, e as composições utilizam traços divisores em tamanhos distintos em cada caso. A distribuição das informações respeita uma hierarquia existente entre secretaria e museu, dada pelo posicionamento na ordem de leitura, espacejamento entre letras - que confere diferentes tamanhos lineares - e tamanho dos caracteres, além do sublinhado que aparece no documento de 1959.

Nos documentos datados a partir da década de 1970, a instituição passou a assinar com a nomenclatura "Pinacoteca do Estado".

Figura 10 Documento, 1970, Pinacoteca do Estado. Original escaneado. Fonte: Acervo Cedoc / Pinacoteca de São Paulo.

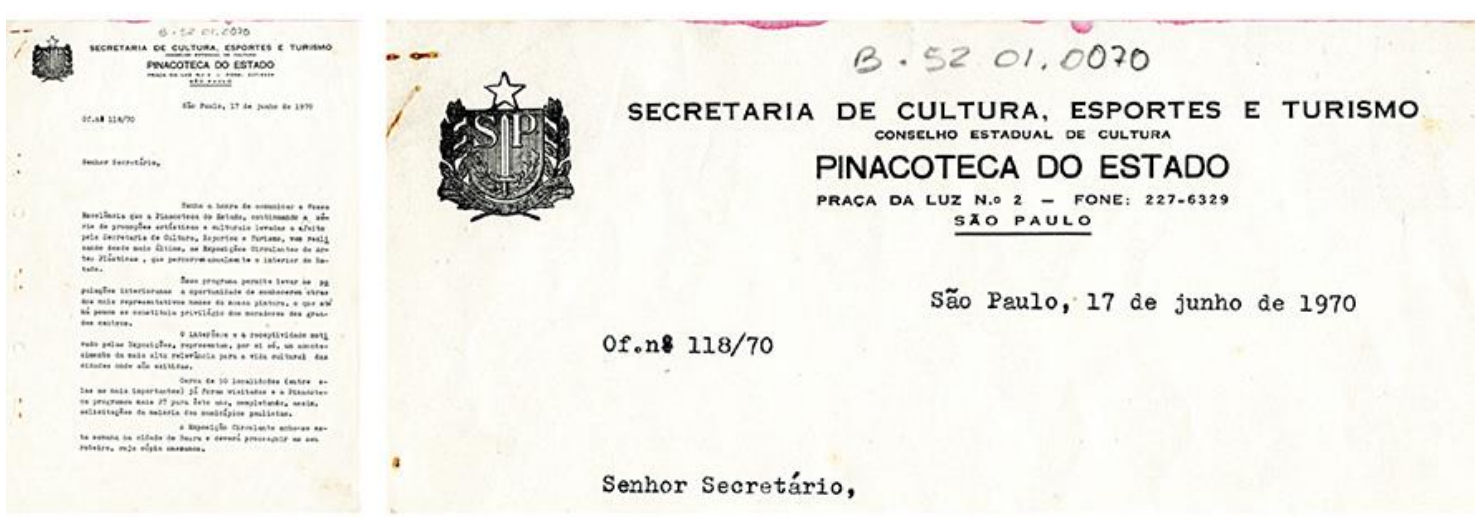

No documento de 1970, a instituição fica subordinada à "Secretaria de Cultura, Esportes e Turismo" e ao "Conselho Estadual de Cultura". Nesse caso, as informações referentes à secretaria foram grafadas em uma tipografia que se diferencia por uma serifa curta - bilateral, fina e pontuda (BRINGHURST, 2005) - e um maior espacejamento entre letras que ocupam o cabeçalho; enquanto a assinatura gráfica da Pinacoteca, o endereço e o telefone compõem um segundo bloco, mais curto, cujas informações foram grafadas em um tipo sem serifa, com tamanho maior na assinatura "Pinacoteca do Estado". A versão do Brasão utilizada segue o modelo publicado em 1948, que, como visto anteriormente, continha deturpações que só seriam corrigidas em 1971.

Figura 11 Documento, 1976, Pinacoteca do Estado. Original escaneado. Fonte: Acervo Cedoc / Pinacoteca de São Paulo.
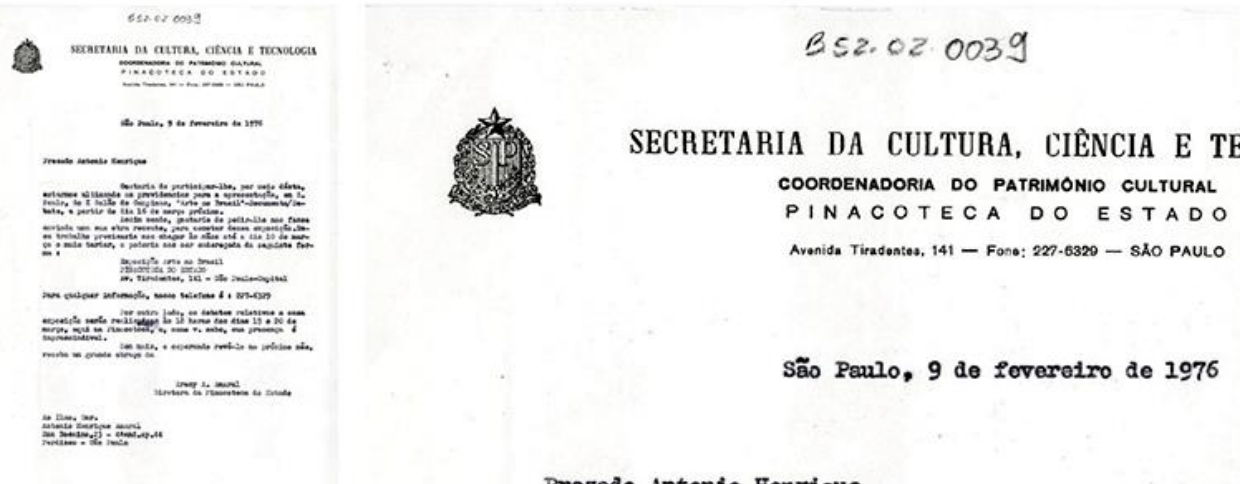

Prezado Antonio Henriaue

A Pinacoteca aparece subordinada à "Secretaria da Cultura, Ciência e Tecnologia" e à "Coordenadoria do Patrimônio Cultural" no documento de 1976, e respondendo ao "Departamento de Artes e Ciências Humanas" no documento de 1977. Na ocorrência de 1976 o nome "Pinacoteca do Estado" aparece grafado com uma tipografia sem serifa, de espessura 


\section{CIDI $2017 \mathrm{~g}^{\mathrm{ln}} \mathrm{CID}$

fina e uniforme, com as letras bastante espacejadas entre si. No documento de 1977 a composição é bastante semelhante, porém a tipografia, sem serifas, apresenta características geométricas (LUPTON, 2006). Aparentemente o espaçamento foi ampliado para que as três linhas - contendo o departamento, a assinatura gráfica da Pinacoteca e o endereço - ficassem com a mesma largura, justificadas. No documento datado de 1976 as linhas parecem ter o mesmo comprimento mas estão desalinhadas, sugerindo alguma dificuldade na composição; no documento datado de 1977 isso parece ter sido corrigido.

Figura 12 Documento, 1977, Pinacoteca do Estado. Original escaneado. Fonte: Acervo Cedoc / Pinacoteca de São Paulo.

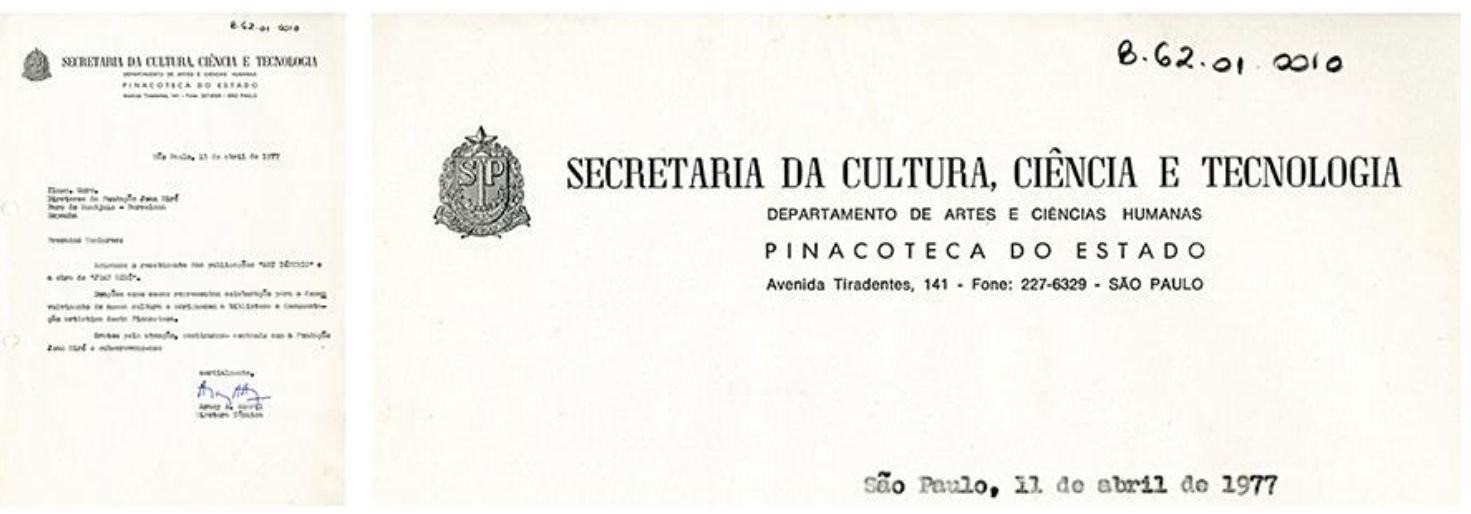

No documento de 1981, a Pinacoteca aparece subordinada à "Secretaria de Estado da Cultura", cuja tipografia, com serifa e de corpo maior, ocupa o cabeçalho. A assinatura gráfica da Pinacoteca foi grafada em tipografia sem serifa, em peso bold, corpo menor, com espacejamento entre letras padrão. Os dados de endereço da Pinacoteca foram grafados em corpo menor, peso regular e justificados com a assinatura da secretaria.

Figura 13 Documento, 1981, Pinacoteca do Estado. Original escaneado. Fonte: Acervo Cedoc / Pinacoteca de São Paulo.
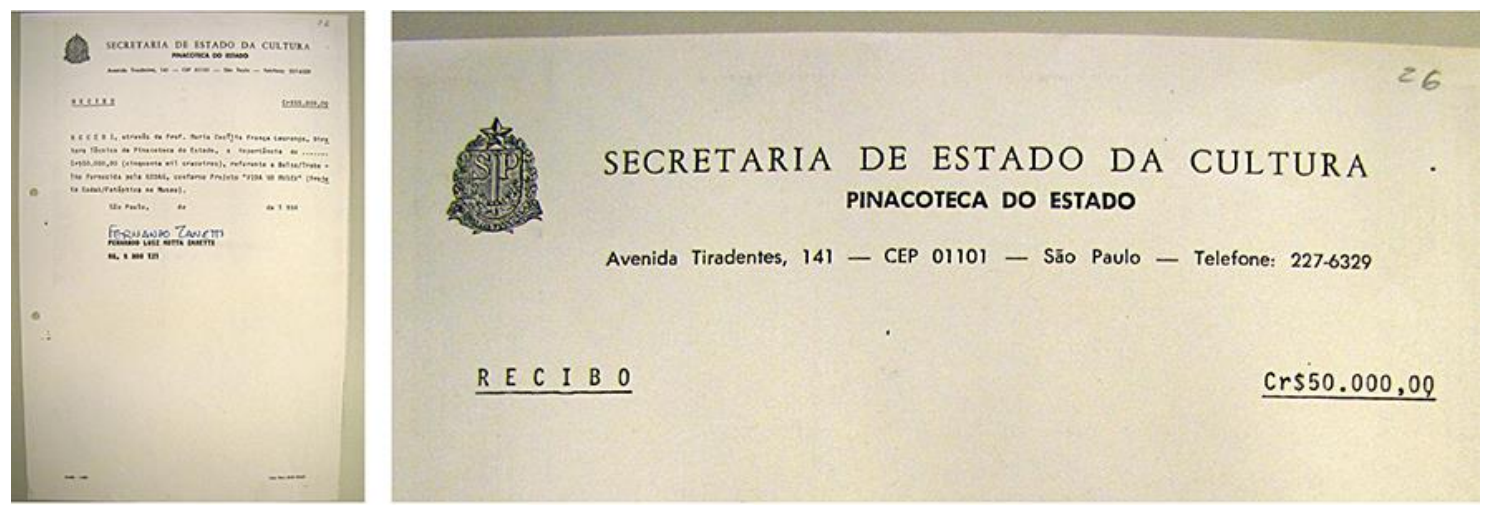

Os documentos oficiais da Pinacoteca pertencentes ao período analisado se caracterizam pela presença do Brasão e do nome de uma secretaria do governo do Estado. De modo secundário, a assinatura gráfica da Pinacoteca aparece ao longo do período com uma inversão da hierarquia tipográfica, em que o nome da instituição foi perdendo destaque, com corpo menor em relação às outras informações nos documentos. Progressivamente a assinatura gráfica ficou atrelada a parâmetros políticos, impostos pelo governo do Estado através da subordinação às secretarias, o que pode ser entendido como uma política geral vigente para as instituições pertencentes ao Estado de São Paulo na época. 
Figura 14 Documentos. Respectivamente: Secretaria de Estado dos Negócios do Govêrno - Serviço de Fiscalização Artística, 1954; Secretaria de Estado da Cultura, 1988. Originais fotografados. Fonte: Acervo Cedoc / Pinacoteca de São Paulo.
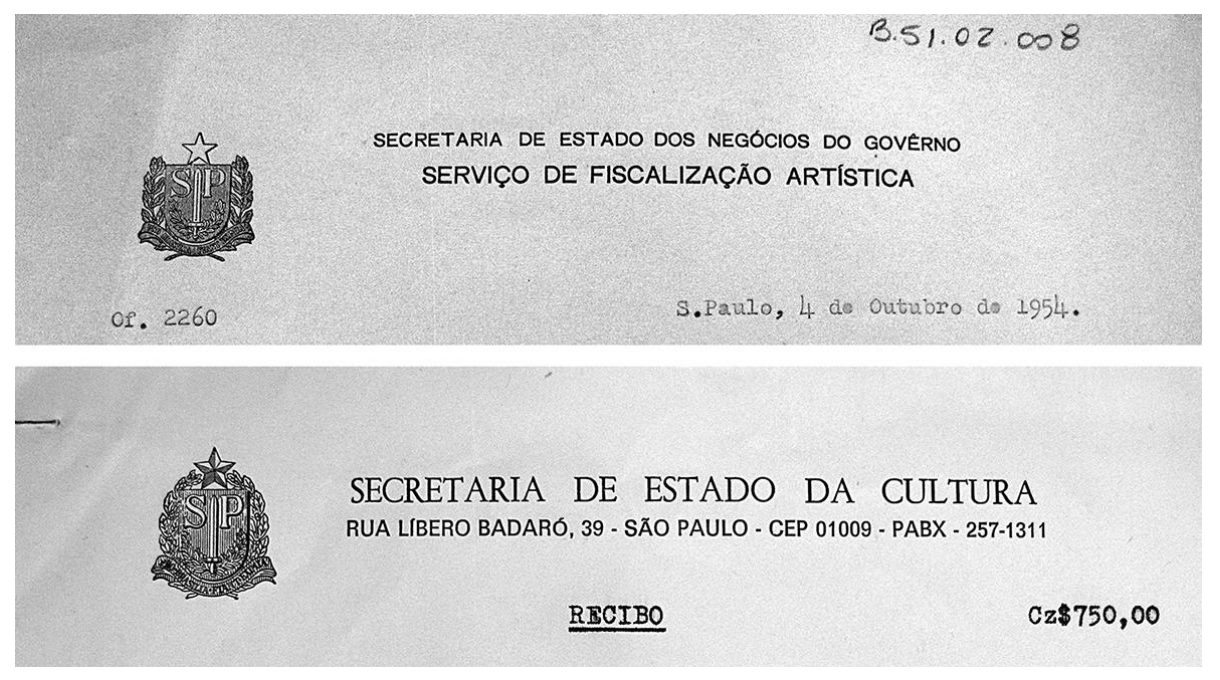

Diante do acervo do Cedoc foi possível observar outros documentos timbrados, que se direcionavam à Pinacoteca, emitidos por diferentes secretarias de governo. Os elementos impressos e as informações que compõem o cabeçalho dos documentos são basicamente os mesmos que foram observados nos da Pinacoteca: o uso do Brasão, o nome da secretaria por extenso, o nome do órgão pertencente àquela secretaria e, em um dos casos, o endereço e telefone. Nesses exemplos figura o Brasão do Estado, datados respectivamente de 1954 - em que a versão incorreta foi reproduzida - e de 1988 - em que foi reproduzida a versão original seguindo as leis da heráldica.

É possível perceber que essa disposição das informações no cabeçalho dos documentos configurava um padrão recorrente e pré-determinado para os órgãos públicos e secretarias de governo, o que também era seguido pela Pinacoteca.

\section{Considerações finais}

Pode ser observado que os catálogos da Pinacoteca da década de 1950 parecem apresentar um leiaute planejado especialmente para a instituição, com traços de documento oficial. As cores vermelho e preto começaram a fazer parte das capas das publicações na mesma década, e foram as primeiras publicações dessa instituição que utilizaram mais de uma cor de impressão, reforçando, juntamente com o Brasão, sua ligação com o Estado.

Um extenso conjunto de documentos oficiais, que abrange um longo período de subordinação da assinatura gráfica da Pinacoteca às secretarias de governo e o uso do Brasão estadual, fez com que o papel da instituição, enquanto equipamento cultural museológico, fosse visualmente vinculado ao Estado, seu mantenedor, anulando qualquer possibilidade de uma identidade visual própria. Tal subordinação ao Governo do Estado, explícita nas assinaturas gráficas, iniciada na década de 1940 e continuada pela década de 1950 em diante, parece refletir a posse do edifício do Liceu pelo Estado em 1944, posto que tal relação com as secretarias não aparecia nas publicações e documentos das décadas anteriores (PIAIA, 2017). Há uma evidente preocupação em vincular a Pinacoteca ao Estado, às secretarias e aos órgãos governamentais, enfatizando que o museu é público, o que se percebe em todos os documentos analisados pertencentes ao período que se estende da década de 1950 até o final da década de 1980. Embora não faça parte do escopo deste artigo, é importante salientar que a relação de subordinação ao Governo do Estado mudou a partir da década de 1990, quando a Pinacoteca ocupou a totalidade do espaço do edifício, mudança que refletiu na identidade visual institucional dali em diante. 


\section{Referências}

ARAGÃO, I. R. et al. 2012. Desenvolvimento de instrumento para analisar os atributos formais das decrições do produto e os logotipos das Imagens Comerciais de Pernambuco. In: 10 P\&D Design - Congresso Brasileiro de Pesquisa e Desenvolvimento em Design. São Luís, UFMA: $1860-1869$.

ASSEMBLEIA Legislativa E. S. P. 1948. Lei № 145, de 03 de setembro de 1948 "Institui a Bandeira e o Brasão do Estado de São Paulo". São Paulo.

$<$ http://www.al.sp.gov.br/repositorio/legislacao/lei/1948/lei-145-03.09.1948.html>, 05/07/2015.

1971. LEI-F, DE 06 DE JULHO DE 1971 "Determina que se observe o desenho do brasão do Estado de São Paulo instituído pelo Decreto 5656, de 29 de agosto de 1932, para cumprimento do disposto no art. 5 da Lei n. 145, de 03/09/1948". São Paulo.

<http://www.al.sp.gov.br/repositorio/legislacao/lei/1971/lei-0F-06.07.1971.html>, 26/07/2016.

BASTOS, H. R. 2010. O lugar de São Paulo na história do design. Arquitextos, São Paulo, ano 11, n.127.04, Vitruvius, 12/2010. <http://www.vitruvius.com.br/revistas/read/arquitextos/11.127/3696>, 19/09/2016.

BRINGHURST, R. 2005. Elementos do estilo tipográfico. São Paulo, SP: Cosac Naify.

CAMARGOS, M. \& MORAES, M. L. 2005. Pinacoteca do Estado de São Paulo, 1885-2005, Cronologia. In: 100 Anos da Pinacoteca: A formação de um acervo. São Paulo: Pinacoteca.

DIÁRIO Oficial E. S. P. 1932. Diário do Executivo: Atos do Governador do Estado. Decreto № 5.656 - de 29 de Agosto de 1932. São Paulo: Imprensa Oficial. N.196, Ano 42ํ, Terça-feira, 30 de Agosto de 1932. <http://www.al.sp.gov.br/norma/?id=131895>, 10/01/2015.

FARIAS, P. L. 2014. On graphic memory as a strategy for design history. In: Tradition, Transition, Tragectories: major or minor influences? [=ICDHS $20149^{\text {th }}$ Conference of the Int. Committee for Design History and Design Studies]. São Paulo: Blucher: 201-206.

FEDERICI, H. 1980. Símbolos paulistas. São Paulo, SP: Conselho Estadual de Artes e Ciências Humanas.

GORDINHO, M. C. 1991. Gráfica: Arte e Indústria no Brasil: 180 anos de história. São Paulo: Bandeirante Editora.

LIMA, P. G., et al. 2012. Memória Gráfica de Pelotas: uma metodologia de análise. In: 10ำ Congresso Brasileiro de Pesq. e Desenvolvimento em Design. São Luís, UFMA: 2226-2236.

LUPTON, E. 2006. Pensar com tipos. São Paulo: Cosac Naify.

PIAIA, J. S. \& PFÜTZENREUTER, E. P. 2016. O uso do Brasão das Armas Nacionais nos catálogos da Pinacoteca na década de 1940. In: Anais do 12ํㅡㄹ Congresso Brasileiro de Pesquisa e Desenvolvimento em Design [= Blucher Design Proceedings, v. 9, n. 2]. São Paulo: Blucher: 356-368.

PIAIA,J. S. 2017. Memória gráfica em museus de arte: assinatura gráfica da Pinacoteca do Estado de São Paulo. Tese (Doutorado) Unicamp. Campinas.

STICKEL, E. J. S. 2004. Uma pequena biblioteca particular: subsídios para o estudo da iconografia no Brasil. São Paulo, SP: EDUSP: Imprensa Oficial.

TWYMAN, M. 1979. A schema for the study of graphic language. In: Kolers, Paul; Wrolstad, Merald \& Bouma, Herman (Eds.). Processing of visible language. New York: Plenum Press, v.1, 117-150.

VILLAS-BOAS, A. 2009. Sobre análise gráfica, ou Algumas estratégias didáticas para a difusão de um design crítico. Arcos Design 5: 2-17.

\section{Autores}

Jade Samara Piaia, Doutora, Unicamp, Brasil, <jadepiaia@gmail.com>.

Edson do Prado Pfützenreuter, Doutor, Unicamp, Brasil, <edson.reuter@iar.unicamp.br>. 